\title{
Long-term dynamics of the zooplankton community in the southern part of the Maloye More Strait (Lake Baikal)
}

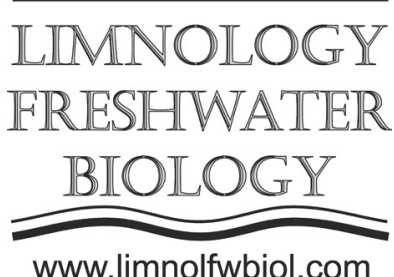

\author{
Sheveleva N.G. ${ }^{1 *}$, Penkova O.G. ${ }^{2}$ \\ ${ }^{1}$ Limnological Institute, Siberian Branch of the Russian Academy of Sciences, Ulan-Batorskaya Str., 3, Irkutsk, 664033, Russia \\ ${ }^{2}$ Irkutsk State University, Karl Marx Str., 1, Irkutsk,664003, Russia
}

\begin{abstract}
We assessed the species composition, dynamics of quantitative indicators and structure of taxonomic groups of zooplankton in the pelagic zone and Mukhor Bay of the Maloye More Strait (Lake Baikal) based on the material from 1997 to 2019. Interannual fluctuations in the abundance and biomass of zooplankton from the bay and the pelagic zone from 1997 to 2019 are within the amplitude of long-term fluctuations for the entire Lake Baikal. Since 2002, there have been significant changes in the structure of the zooplankton community in Mukhor Bay: an increase in the relative proportion of rotifers and a change in dominant species. We recorded a similar restructuring in the zooplankton community from the pelagic zone from 2018 to 2019.
\end{abstract}

Keywords: zooplankton, interannual dynamics, structure of taxonomic groups, Mukhor Bay, pelagic zone, the Malye More Strait, Lake Baikal

Anthropogenic eutrophication of the shallow zone of the world's deepest Lake Baikal has become an urgent problem in recent years (Timoshkin et al., 2015; 2016; Tomberg et al., 2016). Shallow waters of Lake Baikal, playing a role of some ecological buffer, are the first to undertake the anthropogenic impact from the land. The Maloye More Strait is a vast water area enclosed between Olkhon Island and the west mainland coast. In the southern part of the Maloye More Strait, there is Mukhor Bay, one of the most extensive shallow waters of Lake Baikal, with depths of less than $5 \mathrm{~m}$. In 1997, we initiated regular studies of zooplankton in the southern part of the Maloye More Strait, which continue nowadays (Sheveleva and Penkova, 2005; 2016).

With the eutrophication of lakes, structural changes gradually occur, which rather result in the replacement of the dominant species and an increase in their numbers than a change in the species composition. During the evolution of lakes, the structure and functioning of their ecosystems gradually change. Similar changes occur during the anthropogenic eutrophication or pollution. In this case, the processes of the structural and functional rearrangements proceed at a higher rate (Andronnikova, 1996; Alimov, 2017).

We assessed the species composition, dynamics of quantitative indicators and the structure of taxonomic groups of zooplankton in the southern part of the Maloye More Strait (Mukhor Bay and open pelagic zone) according to the long-term observations (from 1997 to 2019). We analysed average data conditionally divided into four periods (from 1997 to 2001; from 2002 to
2008; from 2009 to 2017; and from 2018 to 2019). The periods were distinguished based on the change in the total number of zooplankton and the relative role of the taxonomic group (Table).

Studies over the past 20 years revealed that the zooplankton composition changed insignificantly. Thus, in Mukhor Bay, we detected 63 species, and in the open pelagic zone -37 species. Since 2002, there have been significant changes in the structure of zooplankton in Mukhor Bay compared to the previous years. The changes appeared as an increase in the absolute and relative proportion of rotifers. Thus, the number of rotifers increased by an order a magnitude from 2002 to 2008 and from 2009 to 2017 compared to the 1997-2001 period. Due to this, the total biomass of zooplankton and the relative proportion of cladocerans decreased from 2009 to 2017 and from 2018 to 2019 (Table).

From 2018 to 2019, we recorded changes in the structure of the quantitative indicators of zooplankton from the open pelagic zone of the Maloye More Strait, which resulted in an abrupt increase of the absolute and relative proportion of rotifers in the community. Parallel to this, the relative proportion of copepods decreased, mainly Epischura baikalensis.

The rate of the structural rearrangements in the zooplankton community of the Maloye More Strait is increasing, spreading to the open areas of the Strait. There are reasons to believe that this is the result of the ongoing process of eutrophication.

*Corresponding author.

E-mail address: shevn@lin.irk.ru (N.G. Sheveleva)

(C) Author(s) 2020. This work is distributed under the Creative Commons Attribution 4.0 License. 
Table. Long-term dynamics of the abundance (thou ind. $\left./ \mathrm{m}^{3}\right)$, biomass $\left(\mathrm{mg} / \mathrm{m}^{3}\right.$ ) and relative proportion of abundance (\%) of the main groups of zooplankton (Nrot - rotifers; Ncl - cladocerans; Ncop - copepods) in Mukhor Bay and the open pelagic zone of the Maloye More Strait from 1997 to 2019.

\begin{tabular}{|c|c|c|c|c|c|c|c|c|}
\hline \multirow{2}{*}{ Study period } & \multicolumn{4}{|c|}{ Mukhor Bay } & \multicolumn{4}{|c|}{ Open part of the Strait } \\
\hline & Ntotal/Btotal & Nrot (\%) & $\operatorname{Ncl}(\%)$ & Ncop (\%) & $\mathrm{N}$ total/B total & Nrot (\%) & $\operatorname{Ncl}(\%)$ & Ncop (\%) \\
\hline From 1997 to 2001 & $\frac{57.8 \pm 12}{960 \pm 1223}$ & 7 & 38 & 55 & $\frac{14.1 \pm 3.6}{153 \pm 35}$ & 12 & 8 & 80 \\
\hline From 2002 to 2008 & $\frac{185 \pm 55}{1564 \pm 450}$ & 37 & 20 & 43 & $\frac{37.1 \pm 8,1}{190 \pm 49}$ & 30 & 4 & 66 \\
\hline From 2009 to 2017 & $\frac{139 \pm 39}{885 \pm 180}$ & 51 & 13 & 36 & $\frac{12.3 \pm 2.9}{226 \pm 97}$ & 33 & 10 & 57 \\
\hline From 2018 to 2019 & $\frac{93.7 \pm 14}{821 \pm 480}$ & 41 & 6 & 53 & $\frac{32.3 \pm 18.4}{96.3 \pm 30.5}$ & 88 & 2 & 10 \\
\hline
\end{tabular}

Note: Ntotal above the line is the total number; Btotal below the line - the total biomass (average value with its standard error); Nrot $-\%$ of the total number of rotifers; Ncl - \% of the total number of cladocerans; Ncop - \% of the total number of copepods.

\section{Acknowledgements}

The processing of material and preparation of this article was partially supported by the project No 0345-2016-009 (2017-2019).

\section{References}

Alimov A.F. 2017. Stability and sustainability of water ecosystems. Gidrobiologicheskiy Zhurnal [Hydrobiological Journal] 53(1): 13-23. (in Russian)

Andronnikova I.N. 1996. Strukturno-funktsional'naya organizatsiya zooplanktona ozernykh ekosistem [Structural and functional organization of zooplankton in lake ecosystems]. Saint-Petersburg: Nauka. (in Russian)

Sheveleva N.G., Penkova O.G. 2005. Zooplankton in the southern part of the Maloe More Strait (Lake Baikal). Biologiya Vnutrennikh Vod [Inland Water Biology] 4: 42-49. (in Russian)
Sheveleva N.G., Penkova O.G. 2016. Interannual dynamics of spring zooplankton in the open part of the Maloe More Strait. Gidrobiologicheskiy Zhurnal [Hydrobiological Journal] 52(6): 25-32. (in Russian)

Timoshkin O.A., Bondarenko N.A., Volkova Y.A. et al. 2015. Mass development of green filamentous algae of the genera Spirogira and Stigeoclontium (Clarophyta) in the littoral zone of the southern part of Lake Baikal. Gidrobiologicheskiy Zhurnal [Hydrobiological Journal] 51(1): 13-23. (in Russian)

Timoshkin O.A., Samsonov D.P., Yamamuro M. et al. 2016. Rapid ecological change in the coastal zone of Lake Baikal (East Sibiria): is the site of the worl'd greatest freshwater biodiversity in danger? Journal of Great Lakes Research 42(3): 487-497. DOI: 10.1016/j.jglr.2016.02.011

Tomberg I.V., Sakirko M.V., Onishchuk N.A. et al. 2016. Anthropogenic eutrophication of the littoral zone of Lake Baikal. In: 5th International Conference "Lake Ecosystems: Biological Processes, Anthropogenic Transformation, Water Quality”, pp. 110-111. (in Russian) 